\title{
COLOCANDO EM PERSPECTIVA AS PRÁTICAS DISCURSIVAS DE RESISTÊNCIA EM NOSSAS DEMOCRACIAS CONTEMPORÂNEAS: UMA INTRODUÇÃ̃O'
}

\author{
Luiz Paulo Moita-Lopes* \\ Joana Plaza Pinto ${ }^{* \star}$
}

\begin{abstract}
Por que os movimentos, que contemplam as necessidades e os desejos de tantos, não foram capazes de alcançar mudanças duradouras e de criar uma nova sociedade, mais democrática e mais justa? Essa questão cresce em urgência à media que forças políticas de direita se erguem e tomam o poder em países de todo o mundo, e, então, suspendem procedimentos legais, a fim de atacarem adversários políticos. Solapam a independência do judiciário e da imprensa, realizam operações extensivas de vigilância, criam uma atmosfera de medo entre as várias populações subordinadas, põem noções de pureza racial ou religiosa como condições de pertencimento social, ameaçam imigrantes de expulsão em massa e muito mais.
\end{abstract}

(HARDT; NEGRI, 2017/2018, p. xiii)

$\mathrm{Na}$ vida política, certamente parece que primeiro acontece alguma injustiça e depois há uma resposta, mas pode ser que a resposta esteja acontecendo conforme a injustiça ocorre, e isso nos dá outra maneira de pensar sobre eventos históricos, ação, paixão e vulnerabilidade em formas de resistência. Parece que sem poder pensar em vulnerabilidade, não podemos pensar em resistência, e que ao pensar em resistência, já estamos em andamento, desmantelando a resistência à vulnerabilidade precisamente para resistir.

(BUTLER, 2016, p. 27)

\section{RESISTÊNCIA EM MEIO AO HORROR PERFEITO}

Pouco antes de nos sentarmos para escrever esta Introdução, o chamado bastião da democracia - a Casa do Congresso dos Estados Unidos - foi tomado em

* Pesquisador do CNPq e Professor Titular da Faculdade de Letras da Universidade Federal do Rio de Janeiro, UFRJ, Rio de Janeiro, RJ, Brasil. Email: moitalopes1@gmail.com.

Orcid: http://orcid.org/0000-0002-3829-9824.

** Pesquisadora do CNPq e Professora Titular da Faculdade de Letras da Universidade Federal de Goiás, UFG, Goiânia, GO. joplazapinto@ufg.br.

Orcid: http://orcid.org/0000-0001-8052-9390.

1. Este dossiê responde a um convite-conjunto de Trabalhos de Linguística Aplicada e ALAB (Associação de Línguística Aplicada do Brasil) para celebrar os 30 anos da ALAB. 
6 de janeiro de 2021 por desordeiros que não aprovaram os resultados das eleições presidenciais de 2020. O presidente que está de saída, apoiado por 75 milhões de votos, encorajou essa ação da parte de seus seguidores, como de fato vimos em um discurso seu, transmitido ininterruptamente nas TVs. Ele entende que os resultados foram fraudados, sem evidência aceita nos mais de 50 processos que seus advogados interpuseram às cortes de justiça nos EUA. Os manifestantes provocaram o que tem sido chamado, pelo menos por uma parte da mídia, de 'um assalto à democracia' ou 'uma tentativa de golpe'.

Essa notícia torna-se irônica se considerarmos alguns eventos históricos que atravessaram o globo nos séculos XX e XXI, quando o chamado 'Império Americano’ dominou importante parte do mundo. Ela lançou luz sobre a fragilidade da democracia dos EUA mesmo que este ataque possa ser considerado uma performance bem planejada, um golpe falso ou um 'golpe de propaganda' para a direita radical nos EUA (SARGENT, 2021) - e em outros lugares -, apesar do fato de cinco pessoas terem sido mortas. Essa nação construiu uma história bem propagandeada sobre como age supostamente na defesa da democracia como um valor universal para além de seu território. Com tal justificativa, tem invadido vários países por meio de guerras incontáveis e ajudado a promover golpes de estado que derrubaram governos democraticamente eleitos, como no Brasil em 1964 (MACEDO, 2014), com o suporte inegável de forças das elites locais. Agora, contudo, os EUA enfrentam problemas políticos antidemocráticos em seu próprio território, o que chama atenção para a fragilidade da democracia, como discutiremos a seguir. As alegadas acusações de fraude por parte do presidente em exercício e seus seguidores (incluindo 147 legisladores de seu próprio partido), em última análise, podem levantar dúvidas quanto à validade do sistema eleitoral e das instituições democráticas dos EUA ao redor do mundo.

Como aponta Senna (2021), a 'performance encenada' no Congresso pode ser compreendida como envolvendo a participação de majoritariamente homens brancos arruaceiros que invadiram o Capitólio, carregando bandeiras dos Estados Unidos e confederadas, ofendendo as populações negras, particularmente à luz das recentes manifestações dos movimentos Black Lives Matter. Outros usavam camisetas aludindo aos campos de concentração de Auschwitz e outros a Jesus. Os participantes - sim, no masculino não genérico - evocam as posições de defesas de projetos de dominação masculinista, heterossexista, branca, nacionalista e cristã do mundo, um mantra de uma Modernidade colonialista persistente (MBEMBE, 2014; BAUMAN; BRIGGS, 2003; VENN, 2000). De fato, como vamos esclarecer posteriormente, essas características têm sido apontadas como constitutivas de 
ideais das chamadas extrema-direita, nova direita, direita alternativa (alt-right) ou direita radical - termos usados aqui como sinônimos. Tais ideais têm alimentado projetos políticos contemporâneos em várias partes do globo (TEITELBAUM, 2020; SEDGWICK, 2019; NAGLE, 2017).

Invasões similares têm ocorrido em outros países, igualmente organizados ou estimulados por partidos ou grupos de extrema direita: na Alemanha, na Holanda, na Hungria, por exemplo. Parlamentos e gabinetes de membros dos congressos têm sido invadidos por grupos na defesa de suas agendas contrárias às políticas de vacinas imunizantes da Covid 19, a favor dos interesses de fazendeiros etc. (MUDDE, 2021). Igualmente, no Brasil, o Supremo Federal foi ameaçado de invasão, em 2019, por apoiadores do presidente de extrema-direita que está no poder ao passo que ele próprio aventou a possibilidade de conclamar, em uma manifestação, o exército a agir contra as instituições democráticas.

Surpreendentemente, essas ações antidemocráticas têm sido muitas vezes relatadas na mídia como não tendo merecido a atenção devida por parte das forças de segurança tanto no Brasil como no caso recente dos Estados Unidos (SARGEANT, 2021; LABORDE, 2021), considerando-se, principalmente, o fato de tais ações terem sido planejadas online publicamente (TIMBERG, HARWELL, LANG, 2021). Como veremos posteriormente, é sabido que a Internet é a casa da nova direita, por assim dizer. A pouca atenção da parte das forças de segurança tem levado a que se faça uma associação desses grupos de baderneiros com outros de milícias digitais de extrema-direita, apoiados tacitamente pela polícia. A mídia no Brasil tem levantado também a questão do apoio que o presidente brasileiro tem procurado e recebido enfaticamente da parte dos militares (PEREIRA, 2020; 2021), inclusive quando de suas investidas verbais contra as instituições democráticas.

Pensamos que seja primeiramente necessário colocar esses eventos recentes em perspectiva a partir dos movimentos de expansão da democracia após a Segunda Guerra Mundial para os quais Lessa (2020) chama atenção. Logo a seguir, discutiremos o que Santos (2016) tem chamado de fascismos-sociais recentes assim como a emergência internacional de forças e partidos da direita radical. Por fim, discutiremos as relações entre resistência, vulnerabilidade e poder. Esse cenário sociopolítico e histórico pode colaborar na compreensão dos artigos que constituem esse dossiê temático da TLA, "Resistências em Práticas Discursivas de Contestação em Democracias Frágeis", apresentados ao final da Introdução. Neles, práticas discursivas diversas de resistência a ações de várias naturezas da direita assim como a movimentos antidemocráticos, em várias partes do mundo (Brasil, Inglaterra, Itália, Grécia, Polônia, África do Sul e Israel) são investigadas. 
São também colocadas em confronto a fragilidade dessas democracias como parte de processos históricos coloniais eivados de violências racistas.

Seguindo Santos (2016), compreendemos que muitas de nossas sociedades são "politicamente democráticas [embora sejam] socialmente fascistas". Essas perspectivas, é claro, não se aplicam igualmente (ou com a mesma intensidade) a todos os países cujas práticas discursivas são estudadas neste dossiê embora a necessidade de alargar os horizontes democráticos seja um fator comum a todos eles assim como a muitos outros. Tais práticas discursivas minimamente apontam para sociedades que fomentam o ódio aos (e muitas vezes aniquilam) corpos de imigrantes, negros, mulheres, LGBTIQ+, indígenas, quilombolas etc.

Ao mesmo tempo que Lessa (2020) chama atenção para os vários sentidos que têm sido atrelados ao signo democracia historicamente, diferencia uma visão normalmente dada ao termo pela Ciência Política como modo de governo - uma perspectiva institucional -, e outra enfatizada por ele: a necessidade de aquilatarmos a democracia como uma forma civilizatória ou como uma forma de vida. O pesquisador dá prosseguimento a seu argumento com base no que chama de experimentos democráticos após a Segunda Guerra Mundial. Essa posição ecoa a visão de Santos (2016) quando afirma o fato de muitas democracias poderem ser entendidas como tais institucionalmente, mas serem fascistas em suas realizações sociais, ou seja, podem falhar de uma perspectiva civilizatória ou como uma forma de vida.

Essa compreensão da democracia, conforme Lessa (2020) avalia, se configura por meio de dimensões expansivas: valores ou crenças fundamentais de soberania popular, mas também dimensões relativas à experiência dos direitos individuais, sociais e políticos, que ressoam as visões do liberalismo do século XVII. Tais âmbitos, que podem ser ampliados, ressaltam o fato de que a democracia não tem um limite que não possa ser ultrapassado, ou seja, ela é caracterizada por mobilidade embora não possa ser compreendida como eternamente assegurada. Pode ser ameaçada, interrompida ou mesmo destruída. Essa forma de democracia, após a Segunda Guerra Mundial, ganha uma natureza heterogênea ao juntar partes que não se ajustam exatamente uma vez que as sociedades internamente passam a ser cada vez mais compreendidas em suas diferenças.

Tal entendimento possibilita, contudo, que operemos com um conceito de democracia como uma invenção ou pacto social que garanta direitos cada vez mais iguais. Por exemplo, grupos sociais específicos foram aos poucos incluídos como tendo direito ao voto em momentos e em nações diferentes - homens operários, mulheres, pessoas acima de 16 anos etc. - assim como as proteções relativas a 
direitos sociais foram amplificadas numa grande modernização, que Beck, Giddens e Lash (1995) chamaram de reflexiva. Isso significa que a democracia pode ser vista como um experimento de direitos expansivos ainda que seja caracterizada pelo que Lessa (2020) chama de uma "instabilidade constitutiva", à qual crises são inerentes. A liberdade política, o ambiente político no qual a democracia tem lugar e a salvaguarda social das populações podem ser restringidos ou mesmo destruídos, caracterizando o que Santos (2016) chama de democracias de baixa-intensidade ou mesmo o fim da democracia. Entendemos que a reeleição de chefes de governo na Polônia e na Hungria de extrema-direita, o que não ocorreu nos EUA com Trump, tem levado à sedimentação de governos de baixíssima-intensidade democrática, como identificado, por exemplo, no fechamento de uma universidade na Hungria por motivos políticos e na criação de cidades livres de populações LGBTIQ+ na Polônia. A cristalização desse processo por meio de uma reeleição deve alertar aqueles que têm a democracia em seus horizontes como forma de vida.

As vicissitudes das democracias contemporâneas estão, nas últimas décadas, especialmente tensionadas por turbulências sociais, instituídas por políticas econômicas chamadas de neoliberais - o que não tem nada a ver com os ideais liberais do século XVII já mencionados -, que imperam em muitas partes do globo. Tais políticas têm diminuído flagrantemente as oportunidades no mundo do trabalho e as garantias previdenciárias, implementando a desregulamentação dos mercados, prestigiando a austeridade fiscal e a aplicação de impostos de formas injustamente uniformes etc. (BROWN, 2019; DARDOT; LAVAL, 2009/2016). A uberização do 'emprego' reduz uma grande massa da população a um tipo de quase-escravização contemporânea. Por outro lado, aqueles poucos que se dedicam a práticas rentistas fazem o dinheiro voar daqui para ali ao prazer de seus bolsos, por assim dizer, sem se preocuparem com a devastação social que, sem nenhum pudor, criam localmente. Isso é o que Forrestier (1996) - já há 25 anos, portanto, - denominou O Horror Econômico. Em nossos tempos pandêmicos, esse sistema neoliberal tem levado ao aumento do sofrimento das populações negras, pobres e imigrantes, em uma tanatopolítica devastadora² ${ }^{2}$.

2. Essas chamadas políticas neoliberais são compreendidas como tendo iniciado nos governos de Thatcher e Reagan nos anos 1980. Picketty (2019/2020), porém, enfatiza que o propalado sucesso de tais políticas não se cumpriu. Esse sistema se baseia em imaginações político-econômicas que almejam naturalizar as desigualdades. $\mathrm{O}$ autor aponta que o futuro necessita de uma outra perspectiva. Sugere que outras imaginações sociopolíticas de sucesso do século XX em alguns países, para além de garantir oportunidades de igualdade educacional, sejam consideradas. Indica como alternativas, por exemplo, a modificação da lógica acionária tradicional das empresas, que deveria contemplar os funcionários; a formulação de tributação progressiva; a criação de impostos 
Simultaneamente, essa pauta econômica destrutiva da vida social tem sido acompanhada por políticas sociais igualmente conservadoras e reacionárias. Ainda que a segunda metade do século XX possa ser classificada, em muitos países, como tempos de grandes destradicionalizações sobre a vida sociopolítica (BECK; GIDDENS; LASH, 1995), à custa de muita luta social para garantir os direitos e liberdades civis que expandiram a democracia de modo exponencial (por meio dos movimentos sociais negros, feministas, LGBTIQ+ entre outros), enfrentam-se agora governos ou partidos políticos de extrema-direita, ferozmente empenhados em retroceder os avanços vividos nas práticas sociais que nos levaram a compreender a vida social em outras bases. Temos nos defrontado diariamente com os efeitos de discursos racistas, misóginos, LGBTIQ+fóbicos, anti-imigrantes, contrários à diversidade religiosa, negacionistas da ciência etc. em muitos países.

Do mesmo modo, ações prejudiciais a populações indígenas, ciganas e quilombolas, e de glorificação nacionalista, propagadas pelas mesmas forças políticas, muitas vezes seguindo fundamentalismos religiosos (cristãs radicais, por exemplo), têm ocupado o poder ou aumentado seu alcance em muitos parlamentos mundialmente. Esses retrocessos, com alcances e intensidades diferentes, têm sido identificados no Brasil, EUA, Hungria, Polônia, Índia, Turquia, Filipinas, França, Alemanha, Itália, Grécia, Portugal etc. Podemos dizer que tais forças, lançando mão das redes sociais que dominam nossas vidas onlineOffline, têm operado infecciosamente e são sentidas em práticas discursivo-sociais do dia-a-dia, impingindo diretamente sobre muitos corpos. Isso é então o que podemos chamar, ecoando ainda Forrestier (1996) - de o Horror Sociopolítico contemporâneo. As práticas discursivas de resistência, relatadas nos textos deste volume, contestam justamente tal horror sociopolítico e econômico.

Embora nossos tempos não se confundam com o chamado fascismo histórico (SANTOS, 2016), têm sido compreendidos como tempos que têm feito reviver ideais fascistas, o que já caracterizamos como fascismo social. Tanto Amin (2014), Traverso (2016), Snyder (2018) como Stanley (2018/2019) chamam atenção para o retorno de posições fascistas e, consequentemente, para a falta de liberdade que tem marcado nossas vidas sociais em muitas partes do mundo. Esses autores parecem estar apontando para o que Eco (1995) chamou de fascismo eterno ou Ur-fascismo, que vem recrudescendo nas últimas décadas. Eco, em uma palestra na Universidade de Colúmbia, em 1995, indicou que

sobre grandes heranças e fortunas; e a necessidade de reparação para populações historicamente prejudicadas. É surpreendente que alguns países, como o Brasil, ainda insistam na lógica neoliberal. 
apesar da imprecisão do termo, acho que é possível fazer uma lista de elementos que são típicos do que eu gostaria de chamar de Fascismo Eterno. Esses elementos não podem ser organizados em um sistema; muitos deles contradizem uns aos outros, e também são típicos de outros tipos de despotismo ou fanatismo. Mas basta que um deles esteja presente para permitir que o fascismo se organize em torno dele.

Muitos dos traços que Eco (1995/2018) identifica como fascistas dialogam com capítulos do livro mais recente de Stanley (2018), que explica como o fascismo funciona. $\mathrm{O}$ autor lista entre outras características: o clamor pela volta a um passado nacional mítico quando as condições de vida eram supostamente muito melhores; o uso de propaganda política para esconder os reais objetivos das políticas implementadas, agora na forma da exposição imediata e online das palavras de líderes nas mídias sociais; posições anti-intelectuais por meio de negacionismo científico e, consequentemente, a desvalorização da universidade; e a construção decorrente de uma realidade paralela. Dessa realidade são exemplos: negação dos benefícios de vacinas, o perigo das chamadas 'ideologias de gênero' nas escolas, a promoção de pavor a um comunismo assim como a uma hegemonia pedófila inexistentes, o combate ao que chamam de marxismo cultural, a projeção de uma grande ansiedade sexual sobre as populações, geradora de pânico moral, com base na defesa da família patriarcal, em preocupações doentias com o chamado 'desvio sexual' assim como com o perigo da mistura racial que pode macular 'a raça branca pura', entre outras características.

Não é difícil traçar semelhanças com essas ideias e o que tem caracterizado a chamada extrema-direita, que está no poder em alguns países ou que tem atraído muitos adeptos para seus partidos ou grupos, sobremodo, nas redes sociais em muitos lugares do globo. O presidente eleito no Brasil em 2018, por exemplo, não escondia durante sua campanha suas posições racistas, misóginas, homofóbicas, armamentistas, defensoras de tortura embora, ainda assim, tenha sido eleito. Talvez por, contraditoriamente, se colocar como um cristão evangélico, o que atraiu milhares de religiosos fundamentalistas. Não surpreende assim que "um dos gurus fascistas mais respeitados, [o italiano] Julius Evola", nas palavras de Eco (1995/2018), esteja ainda influenciando o que Sedgwick (2019) nomeou de pensadores-chave da direita radical contemporânea ${ }^{3}$.

Sedgwick (2019) avalia que o pensamento de direita radical retoma com força no século XXI uma vez que os terríveis eventos da Segunda Guerra Mundial e dos

3. No capítulo sobre Evola no livro editado por Sedgwick (2019), Kahl (2019) diz que foi a raiva de Eco (1995/2018) que tornou Evola famoso. No entanto, é impressionante como na Introdução do livro, escrita por Sedgwick, o nome de Evola é citado inúmeras vezes, assim como em Teitelbaum (2020), no qual é discutido o papel de Steve Bannon como articulador da nova direita internacional. 
campos de concentração levaram ao seu temporário esquecimento. Claro que houve partidos de direita no século XX (a chamada Nouvelle Droite na França nos anos 1960 é uma importante referência) assim como houve ditaduras durante o século XX e elas existem até agora, sendo muitas delas marcadas por um pensamento de extremadireita. Muitas dessas inclusive têm sido apoiadas pela assim chamada democracia liberal dos EUA. A América Latina foi e é um parque de diversões, por assim dizer, para tal democracia, agindo em conjunto com as chamadas elites locais, como já aludimos anteriormente. Mas é, no início do século XXI, que muitos partidos de direita radical começam a ganhar força em muitas partes do globo, como Sedgwick (2019) avalia. Sem dúvida, a eleição de Trump, nos EUA em 2016, apresentou e apresenta grandes desafios para a democracia liberal interna nos EUA ao mesmo tempo que ajudou/ajuda a promover o que tem sido chamado de extrema direita ao redor do mundo, tendo em vista a importância econômica (e, consequentemente, de outras naturezas) desse país como 'modelo' a ser copiado.

Reportamos, a seguir, as ideologias principais, orientadoras da direita radical, conforme aventadas em Sedgwick (2019), principalmente aquelas que são mais facilmente identificáveis nas falas de políticos propaladores de tais orientações na vida partidária ou em comunidades onlineOffline. Embora muitos desses ideólogos mais antigos tenham publicado livros, aqueles que Sedgwick (2019) denomina emergentes divulgam suas ideias na Internet. Cabe citar a crítica feita à ideologia da igualdade (a distinção entre 'nós' e 'eles' é constitutiva do pensamento da direita radical $\left.{ }^{4}\right)$; aos movimentos imigratórios, especialmente de imigrantes que professam a religião islâmica nos EUA e na Europa ${ }^{5}$; a elites globalistas desenraizadas e o perigo que representam à desintegração das nações e, em consequência, do que entendem por Ocidente; à mistura racial (as posições em defesa de visões de eugenia são conhecidas na história dos EUA e do Brasil - dois países que receberam grandes contingentes de pessoas negras que foram escravizadas), à mistura étnica (alguns defendem o que chamam de um estado étnico branco como, de fato, identificado nos chamados grupos de supremacistas brancos, advogando que os negros estadunidenses mudem para o sul do EUA e os judeus para Israel); à democracia (visões de hierarquização social são preferíveis); e aos movimentos feministas (alguns defendem sociedades totalmente masculinistas nas quais as mulheres serviriam à

4. Essa mesma distinção ecoa também valores fascistas. Veja o subtítulo de Stanley (2018/2019) sobre o funcionamento do fascismo: A política do "nós" e "eles". Veja também a sobre desigualdade econômica.

5. Nos EUA, os mexicanos estão também entre os indesejáveis assim como os bolivianos no Brasil são desejáveis para a exploração de sua mão de obra barata. Houve, em 2017, manifestações no Rio de Janeiro contra um ambulante sírio, que tirava espaço de camelôs brasileiros, assim como contra seguidores da religião islâmica, acusados de pedófilos e de sequestradores (Rodrigues, 2017). 
reprodução, sendo que outros chegam ao ponto de equacionar o feminismo com anarquia e com o apocalipse, e outros rejeitem vidas LGBTIQ $+{ }^{6}$ ).

Esse quadro ideológico imediatamente nos faz pensar sobre o que, seguindo Lessa (2020) anteriormente, chamamos de "a instabilidade constitutiva" da democracia assim como os revezes com os quais sua expansão se defronta. Da mesma forma, esse quadro tão destrutivo da nossa vida social, por afetar direitos sociais e políticos em expansão na democracia, nos faz repetir a indagação extremamente lúcida de Mbembe (2020) quando discutindo racismo e colonialismo: "Quem são os donos da Terra?". Igualmente, nos faz lembrar a questão de Butler (2009) sobre o porquê de algumas vidas serem mais vivíveis que outras. Entendemos que esses processos que desafiam o crescimento da democracia ou apontam sua fragilidade precisam ser considerados de frente na contemporaneidade, na vida cotidiana e institucional.

Um outro ponto da vida social recente que tem tido papel central no desenvolvimento da direita radical e afetado a democracia, como já adiantamos, é a novidade do uso das plataformas digitais. Muitos pesquisadores, referidos agora por Nagle (2017, p. 25) como ciberutópicos de esquerda (MOITA LOPES, 2012; SÁDABA; GORDO, 2008; por exemplo), viam a Internet como lugar de desenvolvimento das políticas progressistas dos movimentos sociais da qual todos poderiam participar em um mundo de colaborações infinitas. Não atentavam para como as redes sociais poderiam ser usadas para algoritmizar nossas vidas assim como para campanhas políticas como as da empresa Cambridge Analytica (TEILTELBAUM, 2020). Essa algoritmização foi levada a efeito nos Estados Unidos e no Brasil na eleição de partidos de extrema direita, e no Reino Unido, na defesa de políticas que levaram ao BREXIT: parte de um projeto da direita de desintegração da Europa e, de fato, do mundo (TEITELBAUM, 2020, p. 74 e 194).

Além disso, participantes anônimos da internet (uma esfera pública do vale-tudo), sem líderes claros, começaram a usar, massivamente, discursos de ódio e de ameaça à integridade física e moral das pessoas, que entendem como estando em discordância com seus projetos da direita alternativa. Tais discursos são indexicalizados em memes, pranks (trotes) e imagens, apelando ao ultrage sexual e defendendo ideais masculinistas, racistas, LGBTIQ+fóbicos, misóginos, contrários à igualdade, anticomunistas etc. (Nagle, 2017). O que orienta a nova direita tanto na

6. Embora não tenhamos mencionado nenhum dos chamados pensadores da direita radical a não ser o influente Julius Evola, gostaríamos de destacar Jack Donovan (2006) por sua peculiar associação a posições masculinistas radicais de direita. Donovan prestigia a questão de gênero e não a racial ou étnica. Celebra a masculinidade e o amor sexual entre homens, mas rejeita o que chama de cultura gay. Como se pode ver, algumas visões da extrema direita podem contradizer outras. 
internet quanto fora dela é, frequentemente, a provocação de transgressões (muitas de natureza sexual) por meio de trollagens, mentiras e fake-news. Essas surpreendem muitas pessoas por não acreditarem no que estão vendo e/ou ouvindo à medida que igualmente criam pânico moral e fazem com que as populações não prestem atenção às artimanhas políticas em jogo. Essas afrontas produzem, na verdade, uma parede ou cortina de fumaça que esconde o que importa. Como Nagle (2017, p. 17) salienta, "a visão de psicopatia e de rejeição da moralidade imposta perpassa o ethos e a estética das culturas de trollagem de direita". O presidente de extrema direita do Brasil continuamente opera dentro desse ethos e estética e parece assim fazer para incitar terror moral.

Muitos líderes mentem e se desmentem descaradamente, acusam a mídia de provocar caos informacional ao reportar eventos de seus governos enquanto se dizem seguidores cristãos da palavra de Deus. As redes sociais são usadas por eles como lugares para grandes atos de trollagem, que terminam por pautar a mídia tradicional. Tais líderes emulam, desse modo, os participantes anônimos da Internet. Lançam mão de uma performance muito bem ensaiada e estilizada (COUPLAND, 2007) que se diferencia do padrão do político tradicional. Contudo, seus discursos parecem falar àqueles anseios de pessoas racistas, LGBTIQ+fóbicas, misóginas, anti-imigrantes etc., tão combatidos nos anos de correção política ou de ganhos de direitos sociais pela expansão da democracia no passado recente, em muitos países. Talvez reflitam bem de perto a mesquinhez e sordidez humanas, características de políticas do "nós" contra "eles, já referidas, tão presentes nas redes sociais contemporâneas. Em última análise, expressam o prazer com o sofrimento dos outros. Nesse sentido, é marcante a total ausência da parte dos líderes recentes da extrema-direita dos EUA e do Brasil da expressão de compaixão frente ao sofrimento humano. $\mathrm{O}$ grande número de mortes causadas pela pandemia no Brasil não parece ter afetado o presidente brasileiro, por exemplo. Estamos diante da expressão do horror necropolítico ou o Horror Perfeito: a junção entre o Horror Econômico e o Horror Sociopolítico.

Mesmo diante desse quadro histórico, a agora famosa citação de Foucault (1976/1988: 91) sobre a implicação relacional entre poder e resistência é inescapável de nossos pensamentos: "onde há poder há resistência". Isso acarreta dizer que o poder é exercido numa relação, ou seja, é uma operação na qual resistência está implícita. Em tal relação, a ação de resistência atua de dentro do próprio poder. Como dizem Hardt e Negri (2018/2017, p. 104), "a palavra final a respeito do poder é o fato de que a resistência vem primeiro". 
Assumindo uma perspectiva também relacional, Butler, Gambetti e Sabsay (2016) partem do princípio de que a vulnerabilidade não é espaço nem de vitimização nem de paternalismo, mas é a condição para a própria ação de resistência ou, exatamente, "um recurso da resistência" (p. 1). Essa visão, conforme as autoras indicam, questiona a compreensão de que algumas pessoas estão eternamente posicionadas como vulneráveis e sem possibilidade de agenciamento ou de envolvimento em lutas de resistência. Como vimos com Foucault, a resistência está no interior da prática de atuação do poder. Igualmente, vulnerabilidade implica resistência tanto em ações individuais como coletivas, como as autoras salientam.

Esse posicionamento teórico-político repudia "afirmações ontológicas" (BUTLER; GAMBETTI; SABSAY, 2016, p. 2) as quais são carregadas como um fardo de uma inferiorização intrínseca, da qual não se consegue fugir, por corpos de mulheres, LGBTIQ+, negros, de imigrantes, de ciganos, de populações indígenas etc. Uma tal perspectiva implica a necessidade da compreensão dos cenários sociopolíticos, como aqueles traçados nesta Introdução, nos quais vulnerabilidades e resistências são conjuntamente construídas. Especialmente, por que tais corpos ainda que na luta política sejam essencializados, são de fato interseccionados e performatizados diferentemente aqui e agora (CRENSHAW, 1989; SULLIVAN, 2003; BARNARD, 2004): um horizonte que não deve ser perdido de vista e que só se revela situadamente nas práticas discursivas, nas quais as ontologias predeterminadas se desfazem.

Por fim, somos de opinião que, ao pensarmos resistência, cabe avaliar os ganhos políticos do programa teórico-político traçado por Mouffe (2018), intitulado Em direção a um populismo de esquerda. ${ }^{7}$ Se as ações políticas globalizadas da direita radical têm afetado nossas vidas sociais no planeta, a sugestão de usar as translocalizações da mundialização e das redes sociais, como alternativas para promover alianças entre pobres, negros, LGBTIQ+, mulheres, imigrantes etc., como Mouffe (2018) sugere, não parece nem desprezível nem banal. O que parece ser almejado é a criação de força política com base nessas dissonâncias. Afinal, como Sabsay (2016, p. 297) argumenta, "a visão radical da democracia, afinal de contas, parece estar menos preocupada com a realização de um ideal final do que com a mobilização incessante de alianças permeáveis que questionam seus próprios limites". Nesse sentido, uma das possibilidades políticas de um dossiê com pesquisas realizadas em várias partes do mundo, sobre práticas discursivas de resistência, é colaborar na aquilatação de

7. Mouffe (2020) argumenta pela necessidade de considerar a lógica política colocada em operação nos populismos. Em oposição aos populismos de direita, um populismo de esquerda objetiva "ampliar a democracia em muitos domínios e aprofundá-la". 
coalizações transnacionais de resistência que possam ser pensadas em conjunto e experienciadas ou ensaiadas em outros espaços. Esses devem ser pensados como arenas para a imaginação contínua da democracia em sua dimensão expansiva.

\section{RESISTÊNCIA EM PRÁTICAS DISCURSIVAS: UM OLHAR SOBRE OS ARTIGOS}

Com abordagens teóricas diversas, os dezessete artigos desse dossiê (12 em inglês e 5 em português) podem ser localizados no grande campo das pesquisas discursivas na Linguística Aplicada contemporânea. Alguns artigos desenvolvem sua argumentação com base em pesquisas em contextos offline (Araújo, Biar e Bastos; Archakis; Milani et al; Pakuła e Chojnicka; Ribeiro e Gomes; Sena; Silva e Resende; Stroud et al), outros em pesquisas em ambientes virtuais diversificados, como mídias sociais e sites (Borba e Silva; Cavalcanti e Bizon; De Fina; Fabrício e Melo; Marques e Camargo; Morgado; Palma; Sauntson; Silva e Rosado), que muitas vezes se vinculam diretamente a espaços institucionais, como as redes de educação (De Fina; Pakuła e Chojnicka; Ribeiro e Gomes; Sauntson) e de saúde (Fabrício e Melo; Sena).

Os artigos oferecem um panorama amplo das práticas discursivas de resistências em países afetados pelo fortalecimento de discursos anti-democráticos e/ ou de extrema direita (Archakis; De Fina; Milani et al, Pakuła e Chojnicka; Sauntson) ou pela persistência de processos e discursos coloniais desiguais e violentos (Stroud et al), incluindo o Brasil, que experimenta tanto os discursos de extrema direita quanto a persistência das estruturas de violência colonial (Borba e Silva; Cavalcanti e Bizon; Araújo, Biar e Bastos; Fabrício e Melo; Marques e Camargo; Morgado; Palma; Ribeiro e Gomes; Sena; Silva e Resende; Silva e Rosado).

Participantes das práticas analisadas resistem aos projetos necropolíticos da extrema direita e coloniais, como populações negras e quilombolas (Fabrício e Melo; Silva e Resende; Stroud et al), LGBTQI+ (Borba e Silva; Marques e Camargo; Milani et al, Pakuła e Chojnicka; Ribeiro e Gomes; Sauntson; Sena), mulheres (Silva e Rosado), sujeitos periféricos diversos (Araújo, Biar e Bastos; Morgado; Palma), historicamente às margens das promessas da Modernidade, incluindo populações sujeitas a processos migratórios mais recentes (Archakis; Cavalcanti e Bizon; De Fina). Certamente, se destaca no conjunto desses artigos o reconhecimento do racismo como sistema central nas estruturas de desigualdade que se espalharam pervasivamente no mundo a partir do século XV (BERNARDINO-COSTA et al, 2019) e que agora atuam na construção do que chamamos anteriormente de Horror Perfeito. 
Nesse contexto, a resistência é concebida como um agir político performado com recursos semióticos diversos (Cavalcanti e Bizon; Fabrício e Melo; Morgado; Palma), incluindo o corpo (Marques e Camargo; Milani et al; Sena; Stroud et al), mas também como contradiscursos diante de discursos hegemônicos excludentes e violentos, tanto em respostas diretas a esses discursos (Borba e Silva; Araújo, Biar e Bastos; Archakis; Cavalcanti e Bizon; De Fina; Fabrício e Melo; Pakuła e Chojnicka; Ribeiro e Gomes; Sauntson; Silva e Resende; Silva e Rosado) quanto indiretamente, produzindo novos regimes discursivos para novos projetos políticos (Marques e Camargo; Milani et al; Palma; Sena; Stroud et al).

Apresentamos a seguir os artigos organizados de acordo com os tipos de espaços em que as pesquisas foram realizadas. Primeiro as pesquisas offline e em seguida as pesquisas online.

O artigo de Chris Stroud e colaboradores, "Partes do corpo falantes e agenciamentos: dando corpo à cidadania linguística", debate o tema das práticas discursivas de resistência num contexto de persistência da desigualdade histórica na África do Sul pós-apartheid, mas também de movimentos decoloniais como os protestos estudantis contra as taxas das universidades sul-africanas. Nesse contexto, o grupo de autores e autoras, radicados na África do Sul, defendem que, apesar de seu efeito devastador e violento, a vulnerabilidade a que "corpos racializados, sexualizados, generificados e sem deus" estão submetidos, constituídos pela colonialidade-modernidade, pode também ser um local produtivo para a articulação de vozes alternativas habitualmente silenciadas. Para isso, a cidadania linguística é tomada como uma abordagem para voz e agência em cenários de deslegitimação ou perda de direitos linguísticos - especialmente em contextos reconhecidamente multilíngues - mas também de deslegitimação ou perda de voz na arena política. Os autores e autoras apresentam sete vinhetas curtas que ilustram uma variedade de formas em que partes do corpo estão enredadas nos discursos. Com base no potencial dessas vinhetas para produzir locais significativos mais amplos em ordens e espaços públicos, Stroud e colaboradoras(es) apontam como essas ordens são contestadas quando partes do corpo são "resemiotizadas". Corpos são, assim, locais de resistência, na medida em que dão origem/são o tema do discurso, processos e práticas em arenas públicas e, portanto, processos sociopolíticos que fazem emergir novas subjetividades e socialidades.

$\mathrm{O}$ artigo "Quando o ponto de checagem se torna um contraponto: estase como dissidência queer", de Tommaso Milani e colaboradores, busca confrontar o privilégio da metáfora do movimento e da mobilidade nas abordagens críticas das ciências sociais em geral e nos estudos de linguagem, sexualidade e espaço 
em particular. Para isso, os autores analisam três exemplos de dissidência sexual no contexto de Israel/Palestina - um protesto contra o desfile do Orgulho de Tel Aviv decretado por uma coalizão de ativistas israelenses em 2017, pronunciamentos sobre o desfile por parte de diferentes ativistas e acadêmicos palestinos queer e um concerto. Milani e colaboradores argumentam que todos os casos sob escrutínio levam à ideia de estase como uma prática radical queer de rebeldia, expondo a imobilidade como uma forma de ação social e resistência. Eles desenvolvem assim a ideia de que o ponto de checagem (checkpoint) pode tornar-se um contraponto corporal, discursivo e material, oferecendo um potencial de resistência aos regimes de normalidade.

$\mathrm{O}$ artigo "O engajamento em movimentos sociais e a luta por justiça: um estudo sobre as narrativas de mães negras", de Etyelle Araújo, Liana Biar e Liliana Bastos, destacam práticas narrativas de mães e parentes de vítimas de violência policial nas favelas do Rio de Janeiro, todas participantes da Rede de Comunidades e Movimentos contra a Violência. Essas narrativas, geradas durante manifestações públicas, são analisadas como uma conversão do luto à luta política. Ao focarem em como as emoções e o sofrimento são organizados em suas narrativas e em quais estratégias discursivas são usadas nesse processo narrativo, as autoras argumentam que a Rede promove atos de resistência, entendidos como a capacidade de agir coletivamente, perturbar ou alterar os arranjos de poder e promover mudanças estruturais. Elas nos mostram que, ao serem narrados no contexto das manifestações, os eventos que envolvem os assassinatos são recontextualizados e as experiências são coletivizadas, resistindo fortemente à sua invisibilização. Nesse sentido, as ativistas da Rede estão contestando discursos e práticas racistas que historicamente estruturam a abordagem policial e judicial na cidade do Rio de Janeiro. As autoras concluem que essa resistência pressiona por medidas estatais eficazes e transformadoras contra a brutalidade policial e por igualdade judicial.

O artigo "Corpos dissidentes, saúde sexual e microbiopolíticas de resistência na Amazônia Atlântica", de José Sena, foca nas disputas metapragmáticas sobre o cuidado em saúde sexual identificadas em pesquisa etnográfica com estudantes LGBTQI+ em área urbana da cidade de Bragança do Pará, e busca confrontar essas práticas com discursos oficiais, como o Plano Nacional de Saúde Integral LGBT. A etnografia foi desenvolvida ao longo dos anos de 2016-2019, com jovens LGBTI+ no contexto de festas, afterparties e convivências domésticas em repúblicas estudantis da cidade. Baseado na discussão foucaultiana sobre biopolítica e na discussão sobre performatividade, o autor centra-se em performances narrativas de sujeitos LGBTQI+ sobre suas experiências sexuais que disputam metapragmaticamente 
os sentidos do discurso oficial do Estado, identificando nessas performances resistências a uma política de silenciamento e precarização das demandas da saúde sexual dessa população no contexto local. O autor convoca a noção foucaultiana ao descrever essas performances como práticas de resistências microbiopolíticas que questionam o discurso oficial e a manutenção de um regime LGBTfóbico.

Rosimeire Silva e Viviane Resende, em seu artigo "Campanha pela liberdade de Rafael Braga: corpos aliados e a produção de comunidades epistêmicas em resposta à antinegritude", analisam aspectos discursivos do caso da Campanha pela Liberdade de Rafael Braga, jovem negro de periferia, primeiro condenado por suspostamente ameaçar a ordem pública nas manifestações de rua conhecidas como Jornadas de Junho, em 2013, no Brasil. As autoras elegem como base empírica parte de uma etnografia sobre as falas de membros da Campanha pela Liberdade de Rafael Braga e outros atores sociais em torno do tema e artefatos multimodais produzidos nesse contexto de mobilização coletiva. Articulando material etnográfico, entrevistas e textos multimodais, Silva e Resende demonstram nexos e sentidos nas falas que vão do apelo pela liberdade de Rafael à denúncia do cerne antinegritude do projeto brasileiro.

O artigo "Quando a obrigação de ser neutro se transforma no direito de discriminar: embates discursivos sobre os direitos LGBT+ em universidades polonesas", de Łukasz Pakuła e Joanna Chojnicka, discute as narrativas de luta, resistência e contrarresistências sobre os direitos da comunidade LGBT + em várias universidades polonesas. Chama atenção o artigo pela urgência em se debater o avanço do discurso de extrema direita no Leste Europeu e sua relação com a perda de direitos LGBT+, a ponto de as universidades serem mantidas no anonimato no artigo para evitar represálias locais. $\mathrm{O}$ artigo é fruto de pesquisa mais ampla sobre discursos sobre LGBT+ no cenário acadêmico polonês e foca especificamente nos discursos de grupos LGBT + que lutam para estabelecer ou manter organizações (de estudantes até instituições sindicais) dentro da universidade. Com foco empírico em entrevistas semiestruturadas realizadas em 2020, autor e autora mostram uma gama ampla de estratégias de resistência contextualmente empregadas por sujeitos LGBT + para lidar com práticas discriminatórias sistêmicas ou individuais, respondendo em grupo ou individualmente. Convocando a noção de "matriz interagentiva", autor e autora defendem a ampliação dessas estratégias de parcerias entre grupos e instituições para a ampliação e fortalecimento de direitos LGBT+ no contexto acadêmico polonês.

No artigo "Práticas sociodiscursivas de resistência motivadas pela iterabilidade de violências: análise discursivo-crítica dos relatos de homens trans estudantes", 
Samuel Ribeiro e Maria Carmen Gomes analisam práticas sociodiscursivas de resistência produzidas por homens trans estudantes de uma escola pública brasileira, tanto no espaço educacional quanto familiar. No desenvolvimento de sua pesquisa etnográfica, o autor e a autora identificaram representações de práticas violentas, incluindo o não-reconhecimento e a banalização das necessidades particulares de corpos trans estudantes. Segundo Ribeiro e Gomes, essas práticas promovem opressões combinadas em diferentes eixos da diferença, como gênero e raça, mas são contestadas discursivamente com atos discursivos de resistência às práticas cisheteronormativas e normalizadoras.

O artigo de Argiris Archakis, "Narrativas e identidades híbridas de migrantes: análise de narrativas autobiográficas escritas por estudantes migrantes na Grécia", analisa narrativas autobiográficas escritas por estudantes migrantes de ensino médio na Grécia, diante do crescente discurso nacionalista xenofóbico e racista desde os anos 1990. O autor foca num modelo de construção de narrativa de identidade para argumentar que há tentativas de equilíbrio entre as pressões de assimilação a que estão sujeitos no cotidiano de sua experiência migratória, por um lado, e o seu desejo de manter a sua diversidade, por outro, num ambiente etnocêntrico (educacional e social). Archakis destaca como estudantes migrantes se representam como ajustados(as) às expectativas nacionais como resultado de sua vitimização pela maioria, ou seja, quando revelam o racismo que experimentam, eles(as) se contrapõem à maioria coletiva. São formas sutis de resistência através do discurso contra a perpetuação naturalizada da desigualdade social.

Anna De Fina, em seu artigo "Jovens migrantes recuam: Amizades virtuais e resistência cotidiana na esfera digital", assume a resistência como oposição a ideias, situações sociais, ações e processos institucionais que resultam ou podem resultar em discriminação ou estereótipos de grupos sociais específicos. A autora analisa a negociação na esfera digital entre jovens migrantes e não migrantes pertencentes a uma comunidade baseada numa escola na Itália. Numa abordagem etnográfica virtual, a autora seleciona trocas que acontecem numa página de Facebook de uma das participantes de uma comunidade escolar. Usando recursos semióticos próprios dessa mídia, como memes, e repertórios linguísticos variados, a resistência assume muitas formas entre membros e membras do grupo: desde ironia e piadas ao levantamento de temas sérios, à divulgação de informação e através de diferentes géneros discursivos: desde contar histórias até à publicação de imagens. De Fina destaca que os atos espontâneos e discursos de resistência nas trocas cotidianas entre as (os) participantes não nasceram em torno de uma determinada agenda social ou política, mas tais atos funcionam discursivamente contra a discriminação de 
migrantes na Itália, especialmente africanos, num contexto de ascensão do partido de extrema direita neste país (2018-2019).

Daniela Palma, em seu artigo "O cotidiano, a quebrada e o sonho: a resistência pelo olhar na ação de um fotocoletivo", discute a experiência do DiCampana Foto Coletivo, coletivo de fotógrafos profissionais moradores da periferia de São Paulo, criado em 2016, com a proposta de formar uma coleção de imagens da periferia de São Paulo e também de outras cidades do Brasil e da América Latina, contra os estereótipos pejorativos sobre esses espaços que circulam em mídias visuais brasileiras (e também latinoamericanas). Analisando o site do Coletivo, a autora analisa e compreende essa prática fotográfica e ativista como prática de resistência individual e coletiva, na medida em que age politicamente para constituir, pela documentação fotográfica dos lazeres, afetos e prazeres, uma "periferia olhada pela periferia". Com uma abordagem fenomenológica do tempo e do espaço, Palma nos ajuda a compreender as formas como o coletivo propõe uma poética do cotidiano como tempo e espaço de onde as capacidades de resistência emergem, articuladas também com uma poética da sobrevivência, "formas linguísticas, semióticas e midiáticas; formas essas que se fazem no tempo presente das confluências (passado e futuro, tempo e espaço, poesia e narrativa, vozes múltiplas, olhares muitos...), e impulsionam para a transformação" (p. 1866).

O artigo de Branca Fabrício e Glenda Melo, "Nós por nós": enregistramento e desescalação do Coronavírus sob condições nervosas", analisa práticas discursivas muito recentes no Brasil em plena pandemia da COVID-19 e sob um governo de extrema direita. As autoras focam nas práticas de sobrevivência pragmática implementadas pela Frente de Mobilização Maré sob "condições nervosas" (DANGAREMBGA, 1988), ou seja, sob o legado do colonialismo criando persistentemente vida social desigual e injusta. A análise foca na produção e divulgação de material informativo sobre o Coronavírus em linguagem acessível (multissemiótica) em oposição a material informativo oficial em português padrão. As autoras argumentam que o uso de registro linguístico estratégico e a projeção discursiva de desescalamento são táticas de elaboração de informação contra a pandemia de COVID-19 que também funcionaram como estratégias de resistência e construção de uma imaginação sobre o futuro. Tais práticas discursivas reencenam um rastro de reinvenção criativa e resistência, mostrando que "a negociação de ajustes em nossas interações diárias com os textos pode ser a chave para nossa sobrevivência no meio de ideologias destrutivas" (p. 1911).

$\mathrm{O}$ artigo "O pêndulo e as escalas da democracia: 'Epidemia de transgêneros' e resistência à (re)patologização das identidades trans", de Rodrigo Borba e Danillo 
Pereira Silva, analisam a circulação de um poster divulgando uma palestra sobre uma "epidemia de transgêneros", que aconteceria na Assembleia Legislativa de Porto Alegre em março de 2020, e as disputas textuais em torno dessa circulação. Munidos do conceito de escala, os autores argumentam que essas disputas refletem o estado atual da democracia brasileira como produzido na tensão entre projetos escalares distintos. As trajetórias textuais em torno do poster indicam que a recente retração iliberal da sociedade brasileira coexiste com valores e ganhos conquistados em períodos de expansão democrática, fato que explica o cancelamento da palestra devido a protestos online e offline contra sua realização. Os autores argumentam que esse tipo de resistência contesta "projetos escalares desdemocratizantes", fazendo emergir novas coletividades políticas.

O artigo de Djankaw Matheus Marques e Mabia Camargo, "Estudando práticas quilombolas de resistência no Instagram", aborda o Instagram como um espaço potencial para realizar práticas multissemióticas que tanto podem potencializar quanto podem restringir as subjetividades. As autoras focam nos processos de subjetivação performados na mídia social Instagram por uma delas, a autora Djankaw Marques, quilombola negra e trans. De uma perspectiva foucaultiana de análise do discurso, pela qual o poder é ação e seu exercício envolve resistências, as autoras destacam como a resistência é produzida por um conjunto multissemiótico de práticas digitais que afetam o corpo, fotografias, textos e os próprios limites da rede social em foco. Os múltiplos recursos semióticos mobilizados por Djankaw em seu Instagram indicam intersecções de raça, classe, etnia, sexualidade e religião, configurando práticas de resistência contra narrativas hegemônicas coloniais e instigando um debate produtivo sobre a identidade afro-brasileira quilombola. Essas práticas multisemióticas reconfiguram as lutas quilombolas na Web 2.0, resistindo especialmente ao apagamento histórico das culturas quilombolas no Brasil.

No artigo "Fios de uma hashtag: entextualização de resistência face a desafios políticos e sanitários no Brasil", Marilda Cavalcanti e Ana Cecília Bizon também focam no cenário da pandemia de COVID-19 no Brasil, investigando um chamado evento de resistência direta protagonizado por um migrante de origem haitiana. Ao abordar o atual presidente do Brasil e confrontá-lo em sua passagem diária pela área de imprensa do Palácio do Planalto, o haitiano teve sua performance gravada em um celular e postada como um tweet. As autoras focam na viralização dessa postagem, seguindo a hashtag \#acaboubolsonaro decorrente da fala do haitiano. Considerando a confrontação do haitiano como uma performance de resistência e sua entextualização nas redes sociais, as Cavalcanti e Bizon discutem o que chamam 
de "pragmática da resistência" no tecido metarreflexivo das postagens com a hashtag em duas contas do Twitter e algumas das reverberações no Instagram.

Helen Sauntson, em seu artigo "Discursos conflitantes sobre 'democracia' e 'igualdade': uma análise do discurso da linguagem da inclusão pró e anti-LGBTQ+ na orientação de Relações e Educação Sexual para escolas na Inglaterra", analisa as estratégias discursivas utilizadas por grupos de protesto contra e a favor da nova orientação de Relações e Educação Sexual (RSE), que inclui identidades e relacionamentos LGBTQ+, para escolas na Inglaterra lançada em 2019. Para comparar a linguagem dos dois grupos, a autora seleciona vídeos públicos disponibilizados na plataforma YouTube e examina como a linguagem usada pelos grupos a favor da RSE busca resistir ao discurso discriminatório usado pelos grupos anti-LGBTQ+, reenquadrando as ideologias dos grupos contra a RSE nos protestos. Esses discursos conflitantes disputam os significados de "democracia" e "igualdade", já que o mesmo ato normativo no Reino Unido protege religião, identidade de gênero e orientação sexual, sugerindo que estes são conceitos frágeis no atual clima político britânico.

Marcos Morgado, em seu artigo "Mediação da resistência ao fascismo contemporâneo no YouTube: evocando dissidências no Rap brasileiro", busca investigar como a resistência ao fascismo contemporâneo é construída discursivamente nas mídias sociais. Para isso, o autor analisa como material empírico um vídeo de rap em particular, "Primavera Fascista", para apresentar uma análise multimodal de como foi construída a resistência ao discurso do candidato de extrema direita à presidência do Brasil em 2018. Os recursos visuais, sonoros, musicais e linguísticos mostram que a canção de rap é um exercício exaustivo de reflexividade metapragmática sobre os efeitos performativos de uma série de afirmações fascistas produzidas pelo candidato. Para Morgado, os rappers tornamse agentes de resistência em tempos de uma democracia desmoronada, com seu uso da linguagem e sua interação com outros recursos semióticos misturados com grande destreza, eles abrem novas possibilidades para a crítica social.

Marluce Silva e Cid Augusto Rosado, em seu artigo "O furo a qualquer preço': práticas discursivas de poder e resistência ante atitudes machistas em cenário de democracia frágil", focalizam a formação sócio-histórica de produções discursivas. Especificamente, centram na polêmica midiática em torno da ofensa machista feita por Hans River do Rio Nascimento à Comissão Parlamentar Mista de Inquérito (CPMI) das Fake News contra a jornalista Patrícia Campos Mello, da Folha de S.Paulo. Em torno dessa polêmica, muitos enunciados circularam e a autora e o autor focalizam a vontade de verdade e relações de poder e resistência entre 
participantes da polêmica midiatizada. Silva e Rosado buscam discutir a violência de gênero como sintomas de fragilidade democrática, mas também destacam táticas de resistência e transformação.

Boa leitura!

\section{REFERÊNCIAS}

AMIM, Samir. (2014). The return of fascism in contemporary capitalism. Montbly Review, v. 66, n. 4, p. 1-12.

BARNARD, Ian. (2004). Queer race. Nova York: Lang.

BAUMAN, Richard; BRIGGS, Charles L. (2003). Voices of modernity. Language ideologies and the politics of inequality. Cambridge: Cambridge University Press.

BECK, Ulrich; GIDDENS, Anthony; LASH, Scott. (1995). Reflexive modernization. Politics, tradition and aesthetics in the modern social order. Cambridge: Polity Press.

BERNARDINO-COSTA, Joaze et al. (2019). Introdução: Decolonialidade e pensamento afrodiaspórico. In: Decolonialidade e pensamento afrodiaspórico. Belo Horizonte: Autêntica Editora, p. 9-26.

BROWN, Wendy. (2019). In the ruins of neoliberalism. Talk given at the Social Science Matrix "Authors Meet Critics". Video (1h26min). Publicado pelo Canal Matrixssdo Departmental, 12 dez. 2019. Dìsponível em: https://www.youtube.com/ watch?v=0EHVTznPXOE Acessado em: 14 ago. 2020.

BUTLER, Judith. (2009). Frames of war. When is life grievable? London: Verso.

BUTLER, Judith. (2016). Rethinking vulnerability and resistance. In: Butler, Judith, Gambetti, Zeynep; Sabsay, Letícia (eds.), Vulnerability in resistance. Durham: Durham University Press, p. 12-27.

BUTLER, Judith; GAMBETTI, Zeynep; SABSAY, Letícia (eds.). (2016). Vulnerability in resistance. Durham: Durham University Press.

COUPLAND, Nikolas. (2007). Style. Language variation and identity. Cambridge: Cambridge University Press.

CRENSHAW, Kimberle. (1989). Demarginalizing the intersection of race and sex: A black feminist critique of antidiscrimination doctrine, feminist theory and antiracist politics. University of Chicago Legal Forum, v. 1989, n. 1, p. 139-167. 
DANGAREMBGA, Tsitsi. (1988). Nervous conditions. London: The Women’s Press Ltd.

DARDOT, Pierre; LAVAL, Christian. (2009). A Nova Razão do Mundo: ensaio sobre a sociedade neoliberal. Trad. Mariana Echalar. Rio de Janeiro: Boitempo, 2016.

DONOVAN, Jack. (2006). Andropbilia. A manifesto. Rejecting gay identity. Reclaiming masculinity. Baltimore: Scapegoat Publishing.

ECO, Umberto. (1995). Ur-fascism. Disponível em: https://www.pepgc.us. Acessado em: 19 maio 2019.

FORRESTIER, Viviane. (1996/1997). O borror econômico. São Paulo: Editora da UNESP.

FOUCAULT, Michel. (1976). História da sexualidade. Trad. Maria Tereza C. Albuquerque e J. A. Guilhon Albuquerque. Rio de Janeiro: Graal, 1988.

HARDT, Michael; NEGRI, Antônio. (2017). Assembly. A organização multitudinária do comum. Trad. Lucas Carpenelli e Jefferson Viel. São Paulo: Editora Poloteia, 2018.

KAHL, H. Thomas. (2019). Julius Evola and tradition. In: Sedgwick, Mark (ed.), Key thinkers of the radical right. Bebind the new threat to liberal democracy. New York: Oxford University Press, p. 81-96.

LABORDE, Antonia. (2021). Facilidade com que extremistas invadiram o Capitólio derruba chefe da polícia e abre crise sobre segurança. El Pais, 08 jan. 2021. Dìsponível em: https://brasil.elpaís.com/internacional/2021-01-08/chefe-da-policia-do-capitoliose- demite-apos-criticas-pelo-caos.html? capitoliorel=mas Acessado em: 11 jan. 2021.

LESSA, Renato. (2020). Democracia como forma de sociedade e como forma de civilização. Saber comum I Democracia, desigualdade e direitos - Aula 26. Video (32min). Publicado pelo Canal Forum de Ciência e Cultura da UFRJ, 25 dez. 2020. Disponível em: https:// www.youtube.com/watch?v=dKTEub-kOU4 Acessado em: 26 dez. 2020.

MACEDO, Danillo. (2014). Governo norte-americano participa de golpe militar no Brasil. Agência Brasil, 31 mar. 2014. Dìsponível em: https://agenciabrasil.ebc.com.br/ politica/noticia/2014-03/governo-norte-americano-participa-de-golpe-militar-nobrasil Accessado em: 9 jan. 2021.

MBEMBE, Achille. (2014). Crítica da razão negra. Trad. Marta Lança. Lisboa: Antígona, Lisboa.

MBEMBE, Achille. (2020). Out of the darker night (Theory from the margins). Talk given at the Oslo and Johannesburg Seminar. Video (1h44min). Publicado pelo canal Theory 
from the Margins, 24 out. 2020. Disponível em: https://www.youtube.com/ watch?v=sWHYQ6CqP20 Acessado em: 24 out. 2020.

MOITA LOPES, Luiz Paulo. (2012). O novo ethos dos letramentos digitais: modos de construir sentido, revolução das relações e performances identitárias fluidas. In: Signorini, Inês; Fiad, Raquel Salek (eds.), Ensino de línguas: das reformas, das inquietações e dos desafios. Belo Horizonte: Editora UFMG, p. 204-229.

MOUFFE, Chantal. (2018). For a left populism. Londres: Verso.

MUDDE, Case. (2021). What happened in Washington DC is happening around the world. The Guardian, 7 jan. 2021. Disponível em: https://www.theguardian.com/ commentisfree/2021/jan/07/what-happened-in-washington-dc-is-happeningaround-the-world?CMP=Share_iOSApp_Other Acessado em: 7 jan. 2021.

NAGLE, Angela. (2017). Kill all normies. Online culture wars from 4chan and tumblr to Trump and the alt-right. Winchester: Zero Books.

PEREIRA, Merval. (2020). Sem rumo. O Globo, 16 dez. 2020. Dìsponível em: https:// infoglobo.pressreader.com/o-globo/20201216 Acessado em: 16 dez. 2020.

PEREIRA, Merval. (2021). Ainda dá tempo. O Globo, 12 jan. 2021. Dìsponível em: https:// infoglobo.pressreader.com/o-globo/20210112 Acessado em: 12 jan. 2021.

PICKETTY, Thomas. (2019/2020) Capital e ideologia. Transl. Dorothée de Bruchard; Maria de Fátima Oliva do Couto. Rio de Janeiro: Intrínseca.

RODRIGUES, Matheus. (2017). Cariocas fazem fila em 'esfihaço’ para apoiar refugiado sírio agredido em Copacabana. Canal G1, 12 ago. 2017. Dìsponível em: https:// g1.globo.com/rio-de-janeiro/noticia/cariocas-fazem-fila-em-esfihaco-para-apoiarrefugiado-sirio-agredido-em-copacabana.ghtml, Acessado em: 6 jan. 2021.

SÁBADA, Igor; GORDO, Ángel (eds.). (2008). Cultura digital y movimientos sociales. Madrid: Catarata.

SABSAY, Letica. (2016). Permeable bodies. Vulnerability, affective powers, hegemony. In: Butler, Judith; Gambetti, Zeynep; Sabsay, Letícia (eds.), Vulnerability in resistance. Durham: Durham University Press, p. 278-302.

SANTOS, Boaventura de Souza. (2016). A difícil reinvenção da democracia frente ao fascismo social. Entrevista com Roberto Machado. Instituto Humanitas Unisinos, 8 dez. 2016. http://www.ihu.unisinos.br/159-noticias/entrevistas/563035-a-dificilreinvencao-da-democracia-frente-ao-fascismo-social-entrevista-especial-comboaventura-de-sousa-santos Acessado em: 31 ago. 2018. 
SARGENT, Greg. (2021). The far-right Trump insurgency just scored a huge propaganda coup. Washington Post, 08 jan. 2021. Dìsponível em: https://www.washingtonpost. com/opinions/20021?01/8/capitol-mob-far-rigt-trump-propaganda/ Acessado em: 08 jan. 2021.

SEDGWICK, Mark (ed.). (2019). Key thinkers of the radical right. Bebind the new threat to liberal democracy. New York: Oxford University Press.

SENNA, Richard. (2021). 'Tribalismo masculino': a seita violenta ligada ao 'viking' em invasão ao Congresso dos EUA. BBC Brasil, 7 jan. 2021. Dìsponível em: https://www. bbc.com/portuguese/brasil-55582226, Acessado em: 7 jan. 2021.

SNYDER, Timothy. (2019). The road to unfreedom: Russia, Europe, America. New YorK: Tim Duggan Books.

STANLEY, Jason. (2018) Como funciona o fascismo. A Política do "nós" e "eles". Trad. Bruno Alexander. Rio de Janeiro: LPM, 2019.

SULLIVAN, Nikki. (2003). A critical introduction to queer theory. New York: New York University Press.

TEITELBAUM, Benjamin R. (2020). War for eternity: inside Bannon's far-right circle of global power brokers. New York: Dey Street Books.

TIMBERG, Craig; HARWELL, Drew; LANG, Marisa. (2021). Capitol siege was planned online. Rump supporters now planning the next one. Washington Post, 9 jan. 2021. Dìsponível em: https://www.washingtonpost.com/technology/2021/01/09/trumptwitter-protests/ Acessado em: 10 jan. 2021.

TRAVERSO, Enzo (2016). Espectros del fascismo: pensar las derechas radicales en el siglo XXI. Revista Herramientas, v. 58. Dìsponível em: https://herramienta.com.ar/revistaherramienta-n-58/espectros-del-fascismo-pensar-las-derechas-radicales-en-el-sigloxxi Acessado em: 15 ago. 2020.

VENN, Couze. (2000). Occidentalism. Modernity and subjectivity. London: Sage.

Recebido: 23/1/2021

Aceito: 26/1/2021

Publicado: 28/1/2021 